\title{
UTERINE INVASIVE MOLE WITH MICROSCOPIC OVARIAN DECIDUOSIS
}

\section{Rijhsinghani Archana N*}

Junior consultant, Department of Histopathology, SRL Diagnostics Dr Avinash Phadke Labs, Shivaji Park, Dadar, Mumbai- 400028 *Corresponding Author

ABSTRACT An invasive mole (formerly known as chorioadenoma destruens) is a hydatidiform mole that has grown into the muscle layer of the uterus. Invasive moles can develop from either complete or partial moles, but complete moles become invasive much more often than do partial moles. Because these moles invade into the uterine muscle layer, they require chemotherapy and/or surgery.

\section{KEYWORDS : Invasive mole, Hydatidiform mole, muscle layer, uterus.}

\section{INTRODUCTION}

Gestational trophoblastic neoplasia is spectrum of trophoblastic diseases that exhibit progression, invasion and metastatic potential. This terminology includes invasive mole, placental site trophoblastic tumor, and choriocarcinoma. [1]

Invasive mole is a condition where a molar pregnancy, such as a partial hydatidiform mole or complete hydatidiform mole, invades the wall of the uterus, potentially spreading and metastasizing to other parts of the body (such as the vagina or lungs).[2]

About $10-17 \%$ of hydatidiform moles exhibit invasive properties and $15 \%$ progress to distant metastasis.[3]

Overall cure rate in low risk patients is nearly $100 \%$ and in high-risk patient $90 \%$. In rare cases, molar tissue traverses thickness of myometrium and leads to perforation and acute abdomen and invasive mole infrequently metastasis. The best treatment option is chemotherapy (according to stage and score with single or multiple agents) and in patients that fertility is not the matter, hysterectomy can be done. [4]

\section{Case Report}

A 43- year- old female presented with heavy bleeding per vaginum. Ultrasonography showed a mass measuring $10.3 \mathrm{x}$ $9.5 \times 7.4 \mathrm{cms}$ in the endometrial cavity invading myometrium posteriorly. Her beta-hCG level was $239444.39 \mathrm{mIU} / \mathrm{ml}$. Hysterectomy with bilateral salpingo-oophorectomy was performed.

We received bulky hysterectomy specimen measuring $15 \times 8 \mathrm{x}$ $5 \mathrm{cms}$, externally unremarkable. Cut surface revealed bunch of fluid filled vesicles ranging from 0.2 to $2 \mathrm{cms}$ in diameter, and occupying a total of $10 \times 6 \times 4 \mathrm{cms}$. (Figure 1) Foetal parts/ umbilical cord structures/ placental membranes were not seen. Myometrium was focally congested. Both the fallopian tubes and ovaries were grossly unremarkable, except for one ovary showing a cyst measuring $1.8 \mathrm{~cm}$ in diameter.

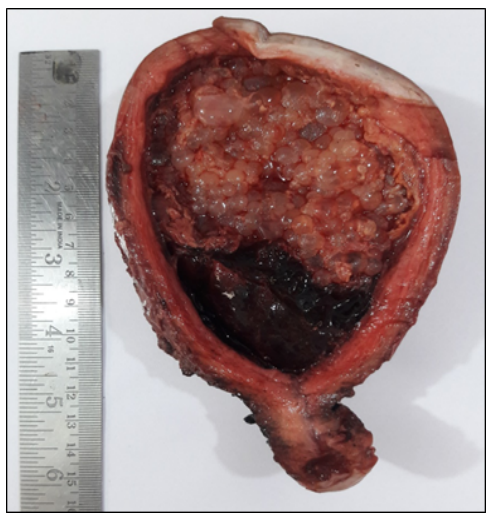

Figure 1: Gross: Uterine cavity showing fluid filled vesicles.
Microscopy revealed complete mole devoid of foetal parts/ umbilical cord structures/ placental membranes. Dilated hydropic chorionic villi surrounded by proliferating trophoblastic tissue (Figure 2) were seen invading myometrium (Figure 3), with absence of decidua at places. Serosa, cervix, bilateral ovaries and fallopian tubes were free of this lesion. One of the ovaries revealed corpus luteal cyst and microscopic deciduosis (Figure 4 and 5).
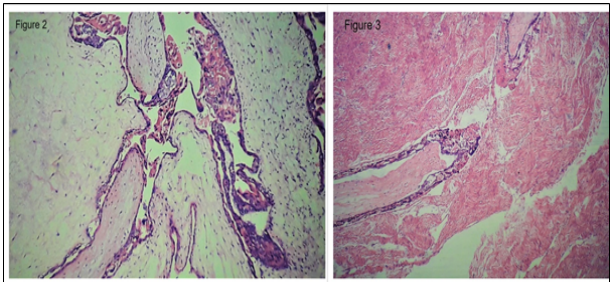

Figure 2 and 3: Microscopy (HE x100) Complete mole showing dilated hydropic chorionic villi surrounded by proliferating trophoblastic tissue (Figure 2), invading myometrium (Figure 3).

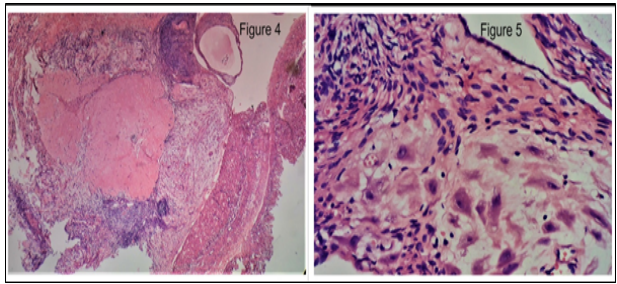

Figure 4: Microscopy (HE x40) Ovary showing corpus luteal cyst and deciduosis.

Figure 5: Microscopy (HE x400) Microscopic ovarian deciduosis.

Thus this is a case of uterine invasive mole on a background of complete mole and ovarian deciduosis.

\section{DISCUSSION}

Gestational trophoblastic disease is a spectrum of cellular proliferations arising from the placental villous trophoblast encompassing four main clinicopathologic forms: hydatidiform mole (complete and partial), invasive mole, choriocarcinoma, and placental site trophoblastic tumor (PSTT). The term "gestational trophoblastic neoplasia" has been applied collectively to the latter three conditions, which can progress, invade, metastasize, and lead to death if left untreated.

Molar pregnancies and gestational trophoblastic neoplasms all take their origin from the placental trophoblast. [3]

Invasive mole is a benign gestational trophoblastic disease that arises from the myometrial invasion of any gestational event via direct extension through tissue or vascular structures. 
Invasive mole, a rare subgroup of gestational trophoblastic disease, is a highly curable and usually locally invasive form of malignancy. Invasive moles are usually diagnosed clinically rather than pathologically when the human chorionic gonadotropin ( $\mathrm{hCG}$ ) levels plateau or rise during follow-up after molar evacuation. Invasive mole often arises after molar pregnancies, but can also rarely occur after any gestation, including miscarriages and term pregnancies. The most common presenting symptoms of the invasive mole are abnormal uterine bleeding and an enlarged uterus. Invasive mole (and other gestational trophoblastic diseases) may present with life-threatening complications including uterine perforation, excessive bleeding, acute hemoperitoneum, and abdominal pain. [5]

A clinical diagnosis of invasive mole can be suspected when beta- hCG titres plateau or increase following evacuation of a mole, but because choriocarcinoma can also supervene in this setting, the clinical diagnosis should be persistent gestational trophoblastic disease. [6]

Hydatidiform moles are commonly associated with markedly elevated hCG levels above those of normal pregnancy. Approximately $50 \%$ of patients with complete mole have preevacuation hCG levels $>100,000 \mathrm{mIU} / \mathrm{mL}$. [3]

Invasive mole may appear as nonspecific heterogenous or hyperechogenic myometrial focal mass with cystic areas in grey-scale ultrasound. A high-resolution ultrasound is very useful in the assessment of myometrial invasion and molar residue after evacuation.[1]

An invasive hydatiform mole is a form of gestational trophoblastic neoplasm that occurs due to abnormal proliferation of placental trophoblast. It is characterized by the presence of edematous chorionic villi with trophoblastic proliferation that invades into the myometrium of the uterus or to adjacent structures such as the vagina, vulva, broad ligament, and can also invade into the uterine vessels. Invasive mole is unlike choriocarcinoma, the latter is without the presence of chorionic villi. It is important to distinguish between invasive mole and choriocarcinoma, as the former has a more favourable outcome. [7]

Ovarian deciduosis has been reported in pregnancy [8], ovarian endometrioma in pregnancy [9]; however it is not yet reported in the invasive mole, to the best of our knowledge.

Invasive mole is highly sensitive to chemotherapy. Combination chemotherapy should be continued in such cases as far as toxicity permits until the patient achieves 3 consecutive normal HCG levels. As normal HCG levels are attained, 3 additional courses of chemotherapy are administered to reduce the risk of relapse. In low risk patients, one or two courses are adequate. Hysterectomy may be required in invasive mole in order to control vaginal bleeding and in unstable patient or in sepsis. Hysterectomy is a reasonable option for patients who do not wish to preserve their fertility, but it does not prevent metastasis. Furthermore, in patients with extensive uterine tumor, hysterectomy may substantially reduce the trophoblastic tumor burden and thereby limit the need for multiple courses of chemotherapy. [4]

\section{CONCLUSION}

This is a rare case of complete mole showing features of invasive mole along with rarer histologic feature of ovarian deciduosis.

\section{Acknowledgement}

The author would like to thank SRL Diagnostics Dr Avinash Phadke Labs.
Financial support and sponsorship

Nil.

\section{Conflicts of interests}

There are no conflicts of interest.

\section{REFERENCES}

1. Budiana I. N. G, Pemayun T. G. A. Diagnosis and Treatment of an Atypical Invasive Mole: A Case Report. Biomed Pharmacol J 2020:13(2):805-808.

2. Gabkika BM, Saleh A, Pazimi T, Paching D, Rimnayal J, Kainba P. Invasive mole of the uterus: A description of one case managed by hysterectomy and chemotherapy. The Journal of Medical Research 2017; 3(5): 217-219.

3. Lurain J.R. Gestational trophoblastic disease I: epidemiology, pathology, clinical presentation and diagnosis of gestational trophoblastic disease, and management of hydatidiform mole. Am. J. Obstet. Gynecol 2010;12:531-539.

4. Aminimoghaddam S, Maghsoudnia A. Unusual Presentation of Invasive Mole: A Case Report. JReprod Infertil 2017; 18(1):205-209.

5. Akyol A, Şimşek M, Üçer Ö. Giant invasive mole presenting as a cause of abdominopelvic mass in a perimenopausal woman: An unusual presentation of a rare pathology. Obstet Gynecol Sci 2016:59(6):548-553.

6. Ie-Ming Shih, Michael T. Mazur, Robert J. Kurman. Gestational Trophoblastic Disease. In: Stacey E. Mills eds. Sternberg's Diagnostic Surgical Pathology. Philadelphia: Lippincott Williams \& Wilkins; 2010. p. 2055-2056.

7. Ahmed Samy El-agwany, Tamer M. Abdeldayem. Invasive mole of the uterus: A description of two cases managed by hysterectomy. Egyptian Journal of Radiology and Nuclear Medicine 2015;46(4):1267-1270.

8. Jeong Hyeon Kim, Ka Hyun Nam, Ja Young Kwon, Young-Han Kim, Yong Won Park. A case of ovarian deciduosis in pregnancy. Korean J Obstet Gynecol 2011;54(7):373-376

9. Izza Rozalli F Rahmat K, Fadzli F Boylan C, Deb P. Decidualized Ovarian Endometrioma in a Pregnant Woman Mimicking Ovarian Malignancy: Magnetic Resonance Imaging and Ultrasonographic Findings. Iran J Radiol. $2015 ; 12(4): \mathrm{e} 21260$ 